\title{
Transnational Cinema: A Cross Culture Communication Medium
}

Manu Sharma*

Amity School of Communication, Amity University, Noida, India

\begin{abstract}
In recent times, in India, as in most other developing nations, there has been an exponential increase in global foray, whether be it of industry, multinational companies, or even art, both popular and otherwise. This has successively made the window of outlook wider and the border more porous, at least figuratively. It is the changes brought about by these transnational elements, mostly, cinema, and particularly those made during the last two decades that formed the core subject of this study.
\end{abstract}

Keywords: Indian films; Indian transnational cinema; Cultural study

\section{Introduction}

The paper entitled Transnational Cinema: A Cross Culture Communication Medium, attempts to look into transnational cinema's innate nature to network the national to the international, not only in the panoptical sense but also with questions related to aesthetics, ideas, and mostly factors pertaining to cross-culture communication, especially in Indian context [1,2]. This paper ascertains the connections and illustrates how transnational cinematic network exhibits and affects the cultural diversities among the various intersecting points as represented by the Indian film media. The study has explored upon the terrains associated with culture and for the same has considered the films, filmmakers and certain other significant visual representations that are Indian creations but have their visual significance in terms of effect beyond the national boundaries. This paper through case specific discourse analysis has researched upon cinema as a medium that makes the immigration of cultural aspects successful, with reference to India.

This study has made an effort to provide an output that will be relevant for cinema as well as cultural studies. Though a lot of work has been done in the field of cinema and culture as two separate domains and that too in terms of international context, but not many researchers have explored upon the mixture of same in the Indian context. The study might help in reshaping the debates on cultural aspect associated with the transnational cinema and can be used by scholars as well as those involved in the practical exploration of transnational cinema with reference to India.

However, this paper doesn't talk about the concept of 'Mass and Popular Culture' or if transnational cinema fulfills the pre- requisites of a popular culture and thus leaves the scope for future study on the same. Also, in addition to films made by NRI's, this paper leaves scope for one to analyze the films depicting the lives of NRI's (Bend it like Beckham) or films exhibiting the cultural changes that are a global as well as a global influence on Indian mindset and have been exhibited through films like Dostana (2008, by Tarun Mansukhani), Zindagi Na Milegi Dobara (2011, Zoya Akhtar), Bong Connection (2006, Anjan Dutt) and films made on the life of NRIs like Dilwale Dulhania Le Jayenge (1995, Aditya Chopra), Kal Ho na Ho (2003, Karan Johar), Kabhi Alvida $\mathrm{Na}$ Kehna (2006, Karn Johar), etc., to name a few. Moreover, due to shortage of time the study has just touched upon the aspect of cross culture communication that has been made possible through Indian cinema.

\section{Literature Review}

\section{Culture and society}

In Indian context, the word culture has been derived from the word 'Kriti', which means the reparation or reformations and is usually referred to as 'sanskriti', which means the cultivation or creation of 'sanskars' (habits, values, beliefs). Elaborating upon the concept of kriti, Leela Samson, in her paper on imbibing Culture at Kalakshetra [3] has stated that, artists in India composed kriti upon kriti in praise of God. There was no sense of ego. The composer did not put a name to his composition, only a dedication to his God. He wrote things that moved him, that pained him. Yet it was not personal.

This explanation talks about culture as a concept which is within 'us' and is not 'only me' and hence it is personal yet it belongs to all. Culture is a constructive modification of the natural course of affairs. As has been stated by Krishnamurti and Bohm in their book, 'The Limit of Thought: Discussion' [4], culture can take the form of some kind of goal- directed cultivation of features or properties of objectsbe those of plants, domesticated animals, or children- in the process of development. It is a value laden term which can be used to designate a group of people who "belong together" by value of shared features. Valsiner has elaborated upon culture by highlighting its essentials, which have been used in the study for the analysis of films. According to Valsiner [5], any culture satisfies three types of relations with its people. Firstly, persons belong to culture, which means that a system guarantees the relative similarity of all the persons who belong to the given culture. Secondly, culture belongs to the persons, which means that cultural means are brought into personal subjective worlds where they transform subjectivities in unique yet culturally guided ways. Thirdly, culture belongs to the relating of persons and the environment, which means that culture, becomes exemplified through different processes by which persons relate with their worlds. Culture belongs to the individual psychological system and plays some functional role in it. A person can belong to different countries, language or ethnic groups or religious belief systems and this social participation un-

*Corresponding author: Manu Sharma, Amity School of Communication, Amity University, Noida, India, Tel: 7852177103; E-mail: manu.sharma209@gmail.com

Received July 21, 2014; Accepted August 18, 2014; Published August 25, 2014

Citation: Sharma M (2014) Transnational Cinema: A Cross Culture Communication Medium. J Mass Communicat Journalism 4: 219 doi:10.4172/2165-7912.1000219

Copyright: (c) 2014 Sharma M. This is an open-access article distributed under the terms of the Creative Commons Attribution License, which permits unrestricted use, distribution, and reproduction in any medium, provided the original author and source are credited. 
doubtly provides material for psychological system within which culture is located.

Culture is dynamic and changes with people and time. Something that was a deep rooted belief system 100 years back can be complimented in future in together with a different mindset 200 years from now. At the end of the day both mindsets are cultural views. This thought can be further exemplified by quoting Singanapalli [6], who has tried to associate cultural values with the concept of freedom in his article on Gandhi's retrieval of Indigenous culture. According to him freedom movement started by Gandhi was an action, a struggle while the viewpoint of today's youth is different as when they comment on Gandhi's attire by stating that at that time it was nothing but an expression of freedom of movement and today it would be nothing but a fashion statement. But at the end of the day, both are the reflection of cultural values at different times of Indian history- of pre and post independent India. According to him, one of the obscurities is that culture is often misunderstood as religion, and at other times as tradition. While culture has connections with religious practices and traditional processes, it is too limiting to consider these as culture itself. Culture simply put, is an accepted way of life; a habit of people, in any group, community or a country; its boundaries extending and contracting depending on the acceptance and commonality ......A culture transcends in time; is more pervasive, and lasts. An idea gets its sustenance and strength from the number of people holding it... culture is democratic, while politics and power by their very nature are hierarchical and control oriented. Culture as a way of living can only be influenced and accepted.

This is so true, as it's possible to destroy an individual holding on to an idea but when it becomes the thought process of a group, it changes into a habit; which at the end of the day is nothing but a culture and thus is difficult to wipe out.

Culture, as per the studies done in the field of signs and symbols has also been referred to as semiotic mediation, which can be intra personal (feeling, thinking, memorizing, forgetting, and planning) or interpersonal (people involved in chatting, fighting, persuading \& avoiding each other or creation of semiotic traps (capturing other person in the web of shame, inferiority, or guilt)). Culture as an action which can also be studied as an option, according to Pierre Janet, Alexey N. Leontiev and John Dewey; Rogoff, is something that humans develop through their participation in socio- cultural activities of their communities, which also changes.

On the other hand Valsiner [5] views culture as a process and believes that the entire transmission and social acceptance of culture can be narrowed down to two models. According to him, It comprises of transfer models- unidirectional (the recipient of cultural transmission or socialization endeavors is passive in the acceptance of cultural messages) and bidirectional (development is open and systematic in which novelty is considered in the process of being created), which view the adaption of an individual to culture in different circumstances of life.

There have been researchers who have viewed culture from a broader prospective and according to them something which is followed by masses is a national culture. According to Hofstede's [7], as has been quoted by $\mathrm{Fu}$ [8] in his paper national Audience Tastes in Hollywood Film Genres: Cultural Distance and Linguistic Affinity, culture is 'the collective programming of the mind' and to classify national Cultures Hofstede [7] has considered the dimensions of individualism/collectivism, power distance, uncertainty avoidance, and masculinity/femininity.
Discussing the concept of culture in context of media, Antara [9] has opined in his paper on News watch: in Search of a National Culture that culture is a dynamic concept and media has a major role to play in its change. According to him, culture.....is developing, constantly morphing set of values and symbols. ....Culture...is a dynamic system of thoughts that allow us to distinguish between and accept or reject situations or acts. We rely on our culture for images and vocabulary that will help us respond to our social and individual environment. Importantly, mass media helps build that culture, besides reflecting it. Culture thus becomes a symbolic system within which all media producers and media users (like readers or viewers) work ....Media operates within a culture and uses its symbols. That includes prejudices and stereotypes

Fortuna [10] in her e- paper on Pirates of the Caribbean and Melville: Using popular culture to interrogate the high western canon has quoted Lakoff \& Johnson while explaining the concept of culture. According to Lakoff and Johnson, culture is the shared ways of people of knowing, thinking, and believing in a symbol-saturated world.

Since the discussion in this paper is restricted to Indian transnational films, so the cultural ethos communicated by transnational cinema have been treated as a 'national culture', this detailed elucidation of culture has created a ground for the discussion on multiculturalism, which in itself is a complex concept and its description can include numerous factors like race, language, religion, culture, etc. However, as per the limited scope of this research, race and culture are the only two issues of multiculturalism that are being discussed in this paper with respect to how these two characteristics find their place in cinema in terms of visual representations, as lately good amount of work has been done by Indian filmmakers to represent the life and cultural conflicts of NRI's settled in UK, USA, and Canada.

To explain the importance of racial aspects of multiculturalism, Valsiner has quoted Schutz, a well-known sociologist, who once wrote an article 'stranger' in which he highlighted the dilemmas of an immigrant. He argued that so long as the immigrant does not accept the culture of host society, he remains a stranger. According to him,

The moment an immigrant adopts the way of life of the host society, he no longer remains a stranger, though the argument is valid for the white European immigrants of the USA. For an Asian and African immigrant the reality is different. The difference in the colour of skin acquires paramount importance in spite of the fact that the myth of superiority of certain races with regard to certain characteristics, like intelligence, courage, inventiveness, etc. has been demolished in biological sciences. In the Western societies, the differences on the basis of the colour of the skin are so obvious and visible that the issue of social inclusion through merging with the way of life of the host society in the phenomenological sense can never work.

Valsiner while trying to explain multiculturalism has quoted Christopher Raj and Andrew Mc Marie [11]. According to them, as far as the analysis of culture in multi-culturalistic society is concerned, the concept is used for the construction of collective self-identity as well as that of others. Despite the fact that accepting culture of the host society is the easiest way to get acceptance, the immigrants invariable perceive the host culture as the greatest threat to their own identity. The normative and value dimension of the culture are part of the socialization process at the individual and collective level. In case of Punjabis in particular, it acquires many dimensions the foremost of which is to save the children from the corrupting influence of western culture. In such a situation, the immigrant community tends to 
insulate itself from all influences that prevent its social inclusion at various levels. As a matter of fact, the nature of construction of the immigrant communities in the West invariably depends upon its level of insulation prevent its social inclusion at various levels. The more insulated you are, the more negatively you will be constructed. The first level of construction that tends to have negative consequences for the immigrants is that instead of making the individual as the locus of understanding in terms of personality, skills and attitudes, the entire community is seen as having common characteristics. The situation in which heterogeneity would discourage and eliminate the possibility of formation of negative stereotypes and prejudices begins to become invisible. At the second level, any single event that could be normatively undesirable turns into the basis of characteristics of the entire immigrant community. The issue of culture in context of immigrants is as complex as the concept of culture. It is generally found that most of the discourses on the issue of culture with regard to the immigrant communities generally implicate the Asians or African.

Supporting the idea of multiculturalism, Fu [8] has stated that adaptation across cultures is easier when they are alike [12,13]. A logical extension is that cinemagoers in respective countries will react to films of a given origin according to their own cultures. In this context, it is expected that the Hollywood film diet of a national audience will depend on the country's cultural distance from the United States

It is interesting to note that how media through different representations portrays culture \& multiculturalism. Havy [14] while explaining the concept of visual communication with respect to cultural studies has stated that, the entire idea of analyzing any culture or making an effort to understand multiculturalism or for that matter the goal of cultural study is to know the meaning of things. The analysts attempts to understand the meaning of one or many cultural texts comprising of books, songs, paintings, cartoons, movies, TV shows, ad films, newspaper articles, fast food restaurants, museum installations, carnivals, human organizations or any other part of the world that can be studied as a text- and through various forms of interpretation.

Grossberg, Nelson and Treichler have Contributed to the understanding of theories and methods involved in the communication through electronic medium, the main elements of cultural studies when seen from the perspective of visual communication as stated on the basis of multiple studies carried out by Grossberg and some done by Him along with Nelson and Treichler include a commitment to observing, understanding \& explaining human action through language and imagery; the acceptance of conflict and contradiction as a central condition of human societies; as interpretative focus on popular texts such as music, movies and TV; the notion that textual meaning is in many ways structured (encoded) within the imagery and language of given text, but that viewers, listeners or readers are final arbiters of textual meaning; an interdisciplinary interest in interpreting texts by borrowing and combining theories and methods from various academic discipline such as communication, linguistics, theory and belief that a given popular culture text is based on familiar culture, specific stories, norms, scenarios, themes, myths, or ideas that can be interpreted critically, within political, historical, economic and social context that shape a text's meaning.

A cultural study is incomplete if it doesn't take the concept of society into account. Society is an abstraction. It's 'us' that shapes 'us', influences our philosophies, makes us learn and unlearn things, helps us in weaving new stories, creating life patterns, adds sense to our existence and at times does things totally senseless. It's 'us'.
According to Valsiner [5], Society is collectively created, and shared, myth story that functions as a sign. Society acts as a semiotic mediatora sign-in human communication process, both between persons and institutions, and as an intra- psychological regulator. As a sign, the society is a hyper-generalized field of significance and such signs are widely used as promoters of our feelings and thinking, as we transverse the myriad of real life settings that we inhabit. They not only provide us with generalized, abstracted knowledge about our worlds, but also carry with them affective suggestions that we use in our everyday ways of living. Our individual selves use not only different assumed needs or duties given to us by society but also notions like justice, love, success, profit and sin, to regulate our relations with others (and with ourselves) in the settings. The society operates in human discourse as a meta-sign that regulates other meanings used in everyday life, by attributing personified agency to an abstract socially constructed entity. Society comprises of social units which are individualistic and collectivistic and these opposites are dynamically related. Demarcation of society into nations, social classes, gender, age groups, professional guilds and castes are also semiotic devices. The rituals, weddings, ceremonies, birth, marriage, psychology of movement projected in any text represents the social institutions that construct the culture.

\section{Cinema as a medium}

Proceeding with the basic understanding of the concepts of culture, multiculturalism, cultural studies and society, this paper has tried to analyze cinema, to be more specific transnational cinema, as a cultural text and focused on the study of audio visual representations of human actions and their conflicts and contradictions in societal context, as this is what the entire framework of this paper revolves around.

It is interesting to note that how cinema has always been talked about as an art, as a medium of communication, as a transporter of different signs, codes and symbols, by intellectuals working on cinema and cinema studies since ages. They have given numerous theories like feminist theory (feminist approach to cinema analysis), formalist theory (analysis the technical elements of films), Auteur theory (analysis of director's creative vision), etc., which somewhere emphasize on the point that cinema as an art form, communicates about different complexities existing in the society, which can be analyzed through numerous ways.

Mertz opines against this viewpoint as according to him, as quoted by Patrick Fuery [15] in his book New Developments in film Theory,.......cinema lacks true communication....films cannot communicate (like speech) because it is invested in expression rather than communication...like communication [16] process one doesn't respond to a film with another film produced at that instant, because is some ways, this is what often takes place. But again everyone has a right to have his/her opinion. Unlike Mertz, researcher strongly feels that cinema is a very powerful medium and holds the ability to communicate with its target audience.

While explaining the concept of abstraction and while justifying cinema as an art, James Monaco [17], in his book how to read a film, has quoted a Greek philosopher who has explained art and its meaning and his conceptualization seems to be applicable to cinema. According to him: art was best understood as a type of mimesis, an imitation of reality dependent on a medium (through which it was expressed) and a mode (the way the medium was utilized). The more mimetic an art is, the less abstract it is and in any situation an art is capable of reproducing reality............ films cover abroad range...., have a 
strong narrative element than any other dramatic art and are capable of reproducing reality.

Moreover, according James, while trying to establish films as a medium of communication has stated that a film manages to communicate meaning through the means of shots, angels, colours, characters, etc,. According to him, they do this essentially in two different manners: denotatively (refers to the strict dictionary meaning of words) \& connotatively (refers to the emotional associations that you think of when you see or hear a certain word) (retrieved from http://english.answers.com/writing-styles/denotative-andconnotative-meanings) [18]. According to him, film images or sound have a denotative meaning: it is what it is and audience don't have to strive to recognize it...... film can give a close approximation of reality, it can communicate a precise knowledge that a written or spoken language seldom can. A language system may be much better equipped to deal with non- concrete world of ideas and abstractions, but they are not nearly so capable of conveying precise information about physical realities. As far as the connotative meaning is concerned film can draw on all the other arts for various effects simply because it can record them. Thus, all the connotative factors of spoken language can be accommodated on a film soundtrack while the connotations of written language can be included in titles. Because film is a product of culture, it has a resonance that goes beyond what semioticians call its diegesis. Moreover, when sense of audience with respect to the connotation of a specific shot depends on its having been chosen from a range of possible other shots, then it can be said that this is using the language of semiotics, a paradigmatic connotation. Audience sense of cinema's connotations depends on understood comparisons of the images that were not chosen (paradigmatic) and images that came before and after (syntagmatic), so sense of the cultural connotations depends upon understood comparisons of the part with the whole (synecdoche) and associated details with ideas (metonymy). Cinema is an art and a medium of extensions and indexes. Much of the meaning comes not from what is seen (or heard) but from what is not seen or more accurately from an ongoing process of comparison of what is seen with what is not seen. This is ironic, considering that cinema at its first glance seems to be an art that is all too evident, one that is often criticized for leaving nothing to the imagination.

As far as the relation between the depiction of society and films is concerned, according to James Monaco, once the work of art is completed it has a sense, a life of its own. The end product i.e., a film, has an influence which spreads, and is most of the time political by nature. No matter how apolitical the work of art may seem, every work has political relevance, like it or not. James ideas strongly support the entire idea of treating cinema as an essential as well as influential medium of communication and somewhere down the line it also indicates that cinema (or if categorically stratified to transnational cinema because of the restricted framework of this paper) has a potential to depict cultural identities and acts as a medium of cross border communication. Semiotics [19], any cultural or cinema studies is largely dependent upon the usage of as well as the analysis of semiotics. Semiotics (also called semiotic studies and in the Saussurean tradition called semiology) is the study of meaning-making. This includes the study of signs and sign processes (semiosis), indication, designation, likeness, analogy, metaphor, symbolism, signification, and communication. Semiotics is closely related to the field of linguistics, which, for its part, studies the structure and meaning of language more specifically. However, as different from linguistics, semiotics also studies non-linguistic sign systems (http://en.wikipedia.org/wiki/Semiotics).
Semiotics in terms of films, according to James Monaco s explained in his book how to read a film, attempts to describe the codes and structural systems that operate in cultural phenomena. It does this by using a linguistic model; that is, the semiotics of film describes film as a language. Since within semiotics one can includes codes and signs, so in terms of films it means the colours, shots, actions used to convey a meaning and the interrelation between them.

According to Patrick Fuery [15], as explained by him in his book New Developments in film Theory, the semiotic analysis looked at the ways in which signs function and interact in the unlimited production and play of meanings. Furthermore, in this interpretation of the production of meanings, semiotics attempts to examine the relationship of this cultural, historical and readerly contexts. This was the major contributions of post structuralism to semiotics analysis that is 'how the meanings are produced, sustained, negotiated and devised' and this should be applicable to all kinds of texts.

While explaining the codes in cinematic context (which supports the cultural framework discussed within the realms of this paper), James Monaco has quoted Hitchcock, who once said that 'codes have meaning for us outside the narrow limits of the particular scene; in film, in the other arts, in the general culture which affects us. The codes are the medium through which the message of the scene is transmitted'. Signs used in films are also a part of codes. According to C.S. Peirce, Peter Wollen, who elaborated on the idea of signs in his book signs \& meaning in the cinema, signs in a films can be of three orders: The Icon: a sign in which the signifier represents the signified mainly by its similarity to it, its likeness; the Index: which measures a quality not because it is identical to it but because it has an inherent relationship to it; The Symbol: an arbitrary sign in which the signifier has neither a direct nor an indexical relationship to the signified, but rather represents it through convention.

Also, in an attempt to break down a film into a smallest unit just like text James Monaco has stated that, film is unlike a written or spoken language and is not composed of units as such, but is rather a continuum of meaning. A shot in a film contains as much information as we want to read in it, and whatever units we define within the shot are arbitrary. Therefore, film presents us with a language (of sorts) that: consists of short circuit signs in which signifier nearly equals the signified; and depends on a continuous, non- discrete system in which we can't identify a basic unit and which therefore we can't describe quantitatively.

Interestingly when the concept of semiotics, signs and codes analysis is applied to a film it looks like a there are different threads that have been woven together to create a collective meaning such that each strand has its own individual identity and has its own independent meaning.

Cinema, in its own way, richly and artistically uses aesthetics. Aesthetics according to Newfield \& Guralink DE, is the study and theory of beauty and psychological response to it. Aesthetic aspects of communication include the visible, structural and configurational elements of image; how implicit is it in apprehension; how holistic is it in conveying meaning; and to what extent is it cognitive in generative sense.

Thus cinema/transnational cinema as an art form, based upon its extensive and elaborative usage of signs, symbols, codes, angles, shots, etc., communicates the complications, intricacies', and densities of society. Cinema in turn uses the prevalent real themes of society and weaves a story around those themes to stimulate or relax or divert its 
audiences from the pre-existing reality. Cinema is also accountable for stressing upon the pre- set standards of the society. This idea has been re- emphasized by a Carolyn Fortuna who in her paper 'Pirates of the Caribbean and Melville: Using popular culture to interrogate the high western canon', by the usage of medium of multi-genre, multimodal, and trans-cultural instruction based discussion in classroom of Florida has quoted the findings of one of her students. During a discussion of particular scene from the film Pirates of the Caribbean, her student stated that;

"..........'Who sets the standard for the text? The characters in the text? No? So, it's the people outside in our society? Like the producer? Like Disney? BJ and Jonathan stepped outside a Disney revisionist world history and considered how composers create characters according to particular ideological views. ...... how some actors have the capacity to exercise social power, domination, and hegemony?"

Since the entire discussion of this paper revolves around transnational cinema, it's time to formerly introduce the concept in the discussion. According to Higbee and Hwee [20] the term transnational cinema:

...is used to indicate international co-production or collaboration instead of looking into the aesthetic, political or economic implications that such international collaboration results. Moreover according to Higbee and Hwee [20], today The term Transnational Cinema has made an increased appearance in subtitles of books to indicate crossborder cinematic connections.

Transnational as a term means extending or operating across national boundaries (retrieved from http://oxforddictionaries.com/ definition/transnational). Transnational cinema, as explained by Vijay Devadas [21], is the cinema made by displaced filmmakers living in exile or diaspora; such that it is used as a mode of expressing the interstitial and artisanal modes of production, distribution and consumption; marked by the use of hybrid stylistic forms, patterns of identification and ideological concerns. Devadas in the same paper holds the perceived insufficiency of National Cinema, Third World Cinema and Third Cinema leading to the rise of the Transnational Cinema as a conceptual category. According to Devadas, Transnational Cinema evolved in order to correspond with and respond to the conditions of the globalized world.

Meanwhile, sociologist Ulf Hannerz and Bergfelder, as quoted by Higbee and Hwee [20]; are of the opinion that 'Transnational' offers a substitute to the generalized and imprecise application of the term 'globalisation'. To drive this point home, they refer to Hannerz's definition of the transnational which is more attuned to the scale, distribution and diversity of such exchanges and their impact at a local level.

Moreover as far as the changes in Indian cinema and its shift from cinema to a niche category of transnational cinema is concerned, Doraiswamy [22] has rightly discussed in her paper on Image and Imagination: Reconstructing the nation in Cinema about the impact of globalization on Indian cinema and how it has segmented the entire film Indian film industry (Hindi Cinema) into three segments. One of these segments also takes into account the era in which the concept of transnational cinema was introduced in India. According to her, globalization has engendered new narratives in the '90s in the Hindi cinema, in which the nation and its imaginings exhibit what can be called a 'deterritoralised' character.

The transnational flow of finance, people, ideologies and images, according to her, now lead to imagings that lie beyond the boundaries of nation state. Thus from nationalism to the post- colonial situation, to the context of globalization, the imaging's of what constitutes the nation in the popular cinema, has undergone many changes The three corresponding moments in post- independence history of Hindi Cinema can be delineated as:

- The aspiration towards a just social order: the period from $40 \mathrm{~s}$ to 60 s.

\section{- Fractured Identities: the 70 s and the 80 s.}

- The cusp of local with the global moment: the 90s end on...

According to her, .....These segments provide a framework to view the way in which narratives have changed in the decades after India achieved independence.

The discussion in this paper majorly talks about the Indian life after 90 s and that too in global context, and how it has been projected through cinema.

Transnational cinema whether it be made by a displaced director or a migrant filmmaker ultimately talks about people and life on both the ends, or in other words, making filmmakers communicate with its variety of audiences about different lives of similar people. It can be exemplified by considering Gurinder Chadha's work, who is of Indian Origin and is a British Director of films like Bhaji on the Beach, Bend it Like Beckham and others. One of the common topics of most of her films is about the life of the Indian immigrants in London, the cultural dilemma they face and the adjustments made to survive culturally. For the Indian community the films of Gurinder Chadha become an entertaining way to look at their peers in a nation other than their own by someone who is essentially like them. Films in India post the economic liberalization, like Dilwale Dulhania Le Jayenge, Kal Ho Na Ho, Kabhie Khushi Kabhie Gham, etc., have been dealing very frequently with the Non-Resident Indians, in short the families that Chadha talks about in her films. So, what is the difference, one might ask. The difference is in perspective. If the former looks at the immigrant to be an outsider the latter does the opposite. This establishes the classic thread of crossborder communication.

One of the most significant aspects or rather phenomena that transnationalism has made possible is the resemblance of places, ideas and verisimilitude of being. This essentially occurs as a result of the permeable nature of transnational cinema to exchange not only people and services but also ideas and aspirations. One of the potent examples in this regard will be the way the hegemony of American media spread all over the world. The American way of life has been deliberately or otherwise, proliferated everywhere and its media that have a great role to play in influencing and homogenizing the media, way of life and culture in other parts of the world. As far as the effect of the transnational media on life is concerned, according to Mirelli [23], it can be illustrated with the example of this tiny state in Northeast India, Mizoram, bordering Myanmar and Bangladesh where there has been this wave of Korean culture fever. And thus we also get a glimpse of transnational cinema not only leading to the exploration of diversity but also its far-reaching effects.

Transnational cinema definitely has effects but despite that its popular and acceptable. As far as the acceptance of transnational media products in general is concerned many researchers [24-27] feel that Media products are created to cater to markets made up of cultural-linguistic consumers. They opine that culture and language are the platforms upon which audiences decode the programs that 
filmmakers have coded. Audience-reception analysts take the view that a society's cultural idiosyncrasies, such as social values, leisure styles, and aesthetic judgments, all elicit active filtering and interpretation of foreign media content by local recipients [28]. In this vein, it is proposed that audiences negotiate foreign programs in a manner molded by the indigenous contexts of the locality, rather than swallowing original meanings wholesale. This active disposition of audiences is also echoed by international media distribution experiences [29]. The acceptance is also influenced by the cultural propinquity audience feel for the product, as has been stated by Straubhaar [30,31], "....audiences tend to prefer and choose media material produced by cultures closer to their own. This suggests that people can better digest and reflect upon content emanating from similar or familiar values, customs, attitudes, and so on".

In context of research studies done on the entire concept $\mathrm{Fu}$ [8], as stated by him in his paper, National Audience Tastes in Hollywood Film Genres: Cultural Distance and Linguistic Affinity, 'empirical research looking at the global coverage of international media flow, however, is rare, although recently more work has been done in this area, partly because of the advent of broader and finer data, and also because more suitable methods have emerged. In his paper he has quoted Fu [32], $\mathrm{Fu}$ and Sim [33], whose research work elevated the understanding of transnational media use from the level of audience acceptance to that of audience taste or preference. In the work of Fu and Govindaraju [34], as has been quoted by $\mathrm{Fu}$ in his paper, they undertook the examination of the new focus of transnational cinema by distinguishing national tastes in Hollywood films, which practically act as a global vehicle for American culture. To measure the similarity of taste between countries, they correlated the popularity of individual films in each one. Using film-level correlation of aggregate audience acceptance, this work, in the technical sense, competently gauged the between-country likeness of content taste, and accordingly advanced our insight into foreign audiences' reception of such widespread cultural goods. But despite these studies still lot work can be done on the analysis of factors associated with the viewing preferences with respect to transnational cinema.

\section{Methodology}

Keeping the essentials of culture, multiculturalism, society and cinema in mind, the study was carried out to fulfill the following Objectives:

- To know how Indian cultural diversities are communicated across borders by Indian transnational cinema.

- To study how Indian transnational cinema uses cultural signs and constructs.

For the attainment of the above mentioned objectives no hypothesis is raised. Also, an in- depth analysis of two films was carried out so as to know that how transnational cinema is connecting people, their culture and is influencing the flow of ideas and aesthetics, in Indian context.

Discourse analysis of two films was carried out. Films have been selected on the basis of purposive sampling, following a case study method. Films selected for analysis as per the research determination were required to fulfill some essential requirements which were-they should have been released between the time period of 1996 to 2005 (so that the time of creation is neither very old nor very new) and they should have been made by NRIs (to understand the Indian cultural representations from their perspective). Following films made by two different directors were found to fulfill the above mentioned variables-
Fire and Monsoon Wedding. Study followed a descriptive research design.

\section{Objective 1}

To know how Indian cultural diversities are communicated across borders by Indian transnational cinema. For the same study analyzed the following variables in two films under study-

a. If representation of characters in films fulfilled three relations needed between a character and culture depicted namely firstly, persons belong to culture, secondly, culture belongs to the persons, and thirdly, culture belongs to the relating of persons and the environment.

b. Do the characters psychologically belong to the social system of the place where they are settled (i.e., despite differences are they allowed to socially participate), as represented in the film

c. Is the semiotic mediation intrapersonal or interpersonal by nature?

d. Are character's adaptations to culture unidirectional or bidirectional?

Though cultural diversity [35] is a broad as well as a complex concept but for the given time study, the analysis of these variables helped in fulfilling the first objective.

\section{Objective 2}

For the fulfillment of second objective i.e., to study how Indian transnational cinema uses cultural signs and constructs, this paper analyzed the usage of different signs in transnational cinema which act as a reflector of societal representations and help in the understanding of culture under study. Signs to be studied in three films were narrowed down to and included-

a. Depiction of relations of justice, love, success, profit, sin, etc.

b. Depiction of individualistic and collectivistic social units

c. Depiction of social institutions associated with Indian culture (via means of rituals, weddings, ceremonies, birth, marriage, and psychology of movement).

d. Depiction of socio-cultural aspects with respect to gender i.e. representation of males/females in terms of power structure. This is to know that are females expected to sit around and look pretty and have less power in taking independent decisions in comparison to males or not and on the other hand are males represented as powerful and decision controllers.

With reference to the second objective related to aesthetics this paper analyzed only the (1) visible structural elements and (2) arrangement of images/visuals in films that fall in the category of Indian transnational cinema and (3) how the innovations in terms of aesthetic aspects of cultural communication have happened.

Variables considered to analyze the visible structural elements included

a. The representation of characters and

b. The evolution of the characters during the story.

c. According to the study, representation of characters can be operationally defined as the portrayal of the character in the formal structure of the film, and signs and symbols used in scenes for the same. 
The evolution of the characters means how the character has changed and/ or developed during the film.

d. Arrangement of images was studied by analyzing how well the shots have been sequenced.

e. Innovation in aesthetics was analyzed on the basis of narrative analysis of films and the cross border cultural exchange. For the same, analysis of language used and its social/cultural context, vocabulary choices made by the director to present an event/character was done.

\section{Description of Films Considered for Analysis}

\section{Fire}

Director: Deepa Mehta: The film is loosely based on Ismat Chugtai's 1941 story, Lihaf (The Quilt). It was one of the first mainstream films in India to explicitly show homosexual relations. The film flashes forward to Sita, a newly married young woman, trying to perceive some emotion from her husband Jatin. Jatin appears distant and shows little interest in Sita or in being married. Jatin is in a typical joint family arrangement. He lives with his older brother Ashok, his sister-in-law Radha, his invalid mother (Biji) and the family servant Mundu.

She is in a typical arranged marriage, but she learns that Jatin married her only to put an end to Ashok's incessant nagging. Jatin continues to date his Chinese girlfriend. Sita spends her days slaving in the hot and greasy kitchen, and she finds herself lonely and frustrated at night because Jatin is out dallying with his girlfriend. Sita resignedly accepts these difficulties, but yearns to break out of this stifling and hopeless situation.

It is later revealed that Radha faces a somewhat similar problem. Many years ago, Ashok had come under the influence of Swamiji, a local preacher, who teaches that desires are the cause of suffering and must be suppressed. Ashok is completely taken by these monastic teachings and accordingly suppresses all his desires. It is also revealed that Radha cannot bear children, due to an untreatable ailment. Accordingly, Ashok aims to stamp out all his desires and has not slept with Radha for the past 13 years. Radha is racked with guilt over her ailment and driven to frustration by the ritual. She resigns to live out her life, but is unable to stop her growing sadness.

Radha and Sita go through the motions oscillating between their desires and disappointments. Radha, the older woman, remains bound by tradition and subdued into silence while Sita refuses to accept misfortune and wishes to break free. One evening, shunned by their husbands, provoked by their (mutual) feelings and driven to desperation by their unfulfilled longings, Radha and Sita seek solace in each other and become lovers. They eventually realise their love for each other and they start looking for ways to move out and be on their own.

Things take a turn for the worse when the servant Mundu becomes aware of their relationship. Ashok is shattered when he finds this incident and nevertheless confronts Radha. Radha overcomes her subservience and pours out her emotions. The film ends with Radha moving out and joining Sita.

\section{Monsoon wedding}

Director: Mira Nair: The film's central story concerns a father, Lalit Verma (Naseeruddin Shah), who is trying to organize an enormous, chaotic, and expensive wedding for his daughter, Aditi (Vasundhara Das), for whom he has arranged a marriage with a man she has known for only a few weeks (Parvin Dabas as Hemant Rai). As so often happens in the Punjabi culture, such a wedding means that, for one of the few times each generation, the extended family comes together from all corners of the globe including India, Australia, Oman, and the United States, bringing its emotional baggage along.

It is a story set in the modern upper-middle class of India, where telecommunications [36] and a western lifestyle mix with old traditions, like the arranged wedding young Aditi accepts when she ends a current affair. The groom is an Indian living in Texas, and all relatives from both families, some from distant places like Australia, come to New Delhi during the monsoon season to attend the wedding. The four-day arrangements and celebrations see clumsy organization, family parties and drama, dangers to the happy end of the wedding, and lots of music.

\section{Content Analysis of Films}

\section{Fire}

The film portrays the components of Indian Dominant Culture. It's a sub culture indicating Hindu religion but the depiction is as per the new times with few fragments of old culture being shown. Protagonist belongs to the new culture. There is no counter culture or deviation from the dominant culture and all the characters associate themselves with the same. However the cultural environment depicted shows a discord between the other characters and protagonist. Protagonist is a combination of ethnocentrism (initially believes in the superiority of own culture) and in the later half her belief shifts to cultural relativism as she though not shown accepting other cultures but questions the logic behind personal culture. Cultural environment is not shown as a hindrance but something that provides guidance and direction to the protagonist. However, all the cultural guidance doesn't make them feel like achievers. Protagonist are forced to follow the culture to which the resistance is shown which further leads to complexities. They participate socially but then again the participation is a forced one. Their semiotic mediation is intrapersonal by nature as most of the time their shown engaged in the act of feeling and thinking rather than of interpersonal nature. Also, during to continuous discord between their feelings and the cultural ethos forced upon them, they can be seen trapped in the semiotic traps. Protagonist adaptation to culture is a mix of unidirectional and bidirectional. As in starts from being passive in the acceptance of cultural messages and then moves on to being open and systematic in the acceptance of new ideas and feelings. The characters have been shown in the relation of love and sin which was shown for 20 to 25 times in the entire film. However, the characters prefer to be in loner social units and their participation in social institutions (associated with cultural environment) is forced one. Male characters shown in the film are controlling. Protagonist were shown developing from being shy characters entering into a wedlock, to strong headed women who is capable of accepting her homo-sexuality publicly. Language being used in the films is a combination of formal as well as informal structures and the dialect is Hindi as well as English. Vocabulary choices were neutral Neuendorf $[37,38]$.

\section{Monsoon wedding}

There's a depiction of Punjabi culture which is a popular Sub culture among the several Indian dominant cultures. One can easily spot the influence of NRI culture on the Punjabi culture form the start of the film, though there is no deviation from dominant culture. The portrayal of this culture is an amalgamation of old and new belief systems. This is so because in the film there's a family preparing for a pompous Punjabi wedding and the protagonist is shown engaged in pre- marital affair, and then there are a couple of other love triangles 
happening inside the house at the same time. But the merger of old and new is a balanced one. Cultural environment accentuated in the film successfully develops a relation between the protagonist and other characters and make them look alike, moving parallel to each other in the chosen social set up. It can be stated that the protagonist is a believer of xenocentrism, where she believes that another culture (western) is better than their own. Despite this feeling, it's depicted that protagonist has a feeling of achievement and some sense of direction because of the cultural environment in which she is being shown. Cultural environment seems to help almost all the characters in getting associated with the environment in a better manner and at the same time they are being shown dealing with their respective complexities. Protagonist is allowed to participate socially and the participation is not forceful but a happy one. Protagonist is engaged in interpersonal setting majority of the times as is shown getting involved in chatting, fighting, persuading and avoiding rather than intrapersonal gestures like feeling, thinking or planning and has been shown engaged in semiotic traps i.e. web of shame (due to her involvement in pre martial affair) and guilt. The adaption to culture is mostly bidirectional, as the protagonist is open to new changes and idea.

Film depicts the relationship of justice, love, success, profit and sin, though the relation of justice and love has been shown the most frequently. Protagonist prefers to stay in groups which somewhere indicates that protagonist has a collectivistic approach towards the social structure. As far as the depiction of social institutions is concerned, scenes showing the rituals, wedding ceremonies, marriage and other psychologies of movement can be spotted very frequently. The depiction has been there for almost $95 \%$ of the times and the characters have been shown enjoying such institutions. Protagonist has been shown as a strong character who is capable of handling the relations with companion or future companions in an assertive manner. The relations between different characters is shown weak initially but as the story progresses, complexities of issues around and their desire to deal with them, makes their relations grow stronger. Language used was a combination of English Hindi, and Punjabi and vocabulary choices were neutral.

Majority of the shots being used in the film include an eye angle shot, close ups which further includes extreme close ups, and long shots that include mid long shot. Slanted angle was missing in the films. The shot have been counted to substantiate and support the sequenced arrangement of the images with respect to the proper flow of story. This is in the fulfillment of second objective (Table 1).

\section{Findings and Conclusion}

From the analysis of these two films belonging to the genre of

\begin{tabular}{|l|c|c|}
\hline & Monsoon Wedding & Fire \\
\hline High Angle & 81 & 7 \\
\hline Low Angle & 110 & 3 \\
\hline Eye Angle & 480 & 10 \\
\hline Slanted Angle & 0 & 0 \\
\hline Aerial Shot & 0 & 0 \\
\hline Close up shot & $\begin{array}{c}234 \text { (includes extreme CU } \\
\text { and CU) }\end{array}$ & $\begin{array}{c}20 \text { (includes extreme CU and } \\
\text { CU) }\end{array}$ \\
\hline Long Shot & $\begin{array}{c}377 \text { (includes Mid long shot } \\
\text { and LS) }\end{array}$ & $\begin{array}{c}28 \text { (includes Mid long shot } \\
\text { and LS) }\end{array}$ \\
\hline Medium Shot & 623 & 12 \\
\hline Wide shot & 37 & 8 \\
\hline Point of view shot & 54 & 0 \\
\hline Misc shots & Yes & Yes \\
\hline
\end{tabular}

Table 1: Shots being used in the film. transnational cinema it can be concluded that the Indian cultural diversities are communicated in a justified manner such that the representations are creatively substantiated with appropriate social set up. For the films with a global perspective it is has been found that they are based on a subculture of the Indian Dominant culture and the portrayal of characters in counter culture is usually avoided. The culture depicted is a combination of old and new one with no major emphasis being laid on either of them. Same goes for the protagonists who were shown following the old as well as the new belief system. However the instituting of similarity between the cultural environment emphasized in the film, and other characters as well as the protagonist depends upon the conceptualization of the film (as it was found similar in Monsoon Wedding and dissimilar in Fire). Also the cultural perspective keeps changing between Ethnocentrism, cultural relativism and xenocentrism, again depending upon the flow of story. Same stands true for the semiotic mediation. In both the films Protagonists were shown gaining some sense of direction because of the culture they were following but feeling of achievement varies with respect to the characters. Social participation is context based (in fire the participation is forced while in monsoon wedding it is lookedfor). Adaptation to the culture is bidirectional by nature, even if it is unidirectional in the beginning. Semiotic traps and relations of love, sin, guilt and shame have been used in both the films. Protagonists in both the films are shown as individualistic personalities though at times enjoy being a part of collective units. It has been found that of social institutions associated with Indian culture like means of rituals, weddings, ceremonies, marriage, and several other cultural establishments depicting the psychology of movement have been frequently used in both the films from which it can be concluded that no Indian transnational film is complete without the on screen description of Indian social institutions. However this description was more elaborately shown in Monsoon Wedding in comparison to Fire and the level of enjoyment with respect to the protagonist was also more in Monsoon Wedding. In Fire males have been represented as powerful and decision controllers while in Monsoon Wedding the control shifts from men to women so it is concluded that the depiction of socio- cultural aspects with respect to gender varies depending upon the context of the story; and transnational cinema not always shows the dark side of the authority ownership with reference to India. In terms of aesthetics and image arrangement medium shot (to give normal perspective to the scene) is the most used one followed by the eye angle shot (to add neutral effect without any dramatic power being added to the scene).

From the findings, taking the objectives into consideration it is be concluded that Indian Transnational cinema communicates the Indian cultural diversities in a most creative manner with the efficient usage of colors, cultural signs and constructs across the borders. But, however the creative communication stays restricted to the depiction of socioethnic establishments and the existing philosophies, issues; problems are not given much time space. Though an interesting observation is that Indian transnational films explore upon themes which combine the 'not much talked about' concepts with the popular concepts. In Monsoon Wedding it's the Punjabi wedding combined with not much openly discussed issue of child abuse while in Fire it was the married life of majority of Indian women united with the concept of homosexuality. Also, the protagonists are always shown bidirectional and the concepts selected by transnational cinema are either based on the dark side (negative perspective) of Indian culture or it showcases a rosy picture.

Also, from this discourse analysis it can be concluded that Indian 
transnational cinema definitely points towards the changes that have taken place in the post liberalization era of Indian cinema and Indian lives. It has in a way has become a strong platform for expression of the followers of modernity, multiculturalism and an indicator of the consequences of movement for Indian migrants. It also conveys that how these three concepts have affected the creative aspect of Indian cinema and the Indian society on the whole. Despite all the loopholes in its production Indian transnational cinema is determined to project more people centric issues on the global platform rather than being commercialized. It's a different genre which is in its growing stage and is trying to create a uniqueness and individuality that is totally different from the overriding Bollywood industry which presumes that it is true and sole representative of Indian film industry. Indian transnational cinema is a pointer of the extension of Indian ideologically at a global level and such films in a way experiment and challenges the mundane representation of complexities that are a feature of in Indian class, gender, and issues related to sexuality. They represent well the life of present day youth who are tied up and jumbled between the thought process of old and new. With its growing market, it has a way to go and can learn a lot from other regional/transnational industries like that of US, Hong Kong, Thailand, etc.

\section{References}

1. Definition of Network

2. Definition of transnational.

3. Leela S (2003) Imbibing Culture at kalakshetra. Max Muller Publisher, India International Centre Quarterly. Winter 2002- Spring 2003 29: 39-46.

4. Bohm D, Krishnamurti J (1999) The Limits of Thought: Discussion. Routledge.

5. Valsiner J (2007) Cultures in minds and Societies: Foundations of Culture Psychology. India: Sage publications.

6. Balaram S (2003) Gandhi's Retrieval of Indigenious Culture. Max Muller Publisher, India International Centre Quarterly Winter 2002- Spring 2003, New Delhi, India.

7. Hofstede GH (2001) Culture's consequences: Comparing values, behaviors, institutions, and organizations across nations. Thousand Oaks, CA: Sage Publications, USA

8. Fu WW (2012) National Audience Tastes in Hollywood Film Genres: Cultural Distance and Linguistic Affinity. Communication Research, Sage Publications 40: 789- 817

9. Antara DS (2003). News Watch: in Search of a National Culture. Max Muller Publisher, India International Centre Quarterly Winter 2002- Spring 2003 29: 275- 288.

10. Fortuna C (2013) Pirates of the Caribbean and Melville: Using popular culture to interrogate the high western canon. The South East European University Language Centre. Journal for Teaching and Learning

11. Raj Christopher, Andrew Mc Marie (2009) Multiculturalism: Public Policy and Problem Areas in Canada and India. Manak Publication Pvt. Ltd.

12. Ellingsworth HW (1983) Adaptive intercultural communication. In: WB Gudykunst (eds), Intercultural communication theory: Current perspectives. Beverly Hills, CA: Sage.

13. Kim YY (2001) Becoming intercultural: An integrative theory of communication and cross-cultural adaptation. Thousand Oaks, CA: Sage publications, USA.

14. Havy JC (2005) Handbook of Visual Communication: Theory, Methods, and Media (Routledge Communication Series: An essay on Burkean Analysis of a TV Promotional advertisement. Lawrence Erlbaum Associates, Publishers.

15. Patrick F (2000) New Developments in film Theory. Palgrave Publishers Ltd New York.

16. Hasan S (2010) Mass communication: Principles \& Concepts. CBS Publishers and Distributors Pvt. Ltd: New Delhi, India.

17. Monaco J (2001) How to Read a Film: Movies, Media and Multimedia. New York: Oxford University Press.
18. Definition of denotative and connotative concepts.

19. Semiotics

20. Higbee W, Hwee S (2010) Concepts of Transnational Cinema: Towards a critical Tran nationalism in film studies. Transnational cinemas journal.

21. Devadas V (2006) Rethinking Transnational Cinema: The Case of Tamil Cinema. Senses of Cinema. Issue 41.

22. Doraiswamy R (2003) Image and Imagination: Reconstructing the nation in Cinema. Max Muller Publisher, India International Centre Quarterly Winter 2002- Spring 2003, New Delhi, India.

23. Mirelli A (2011) Paris, Milan, Dimapur.

24. McAnany EG, Wilkinson KT (1996) Mass media and free trade: NAFTA and the cultural industries. Austin: University of Texas Press, USA.

25. Sinclair J (1996) Mexico, Brazil, and the Latin World. In: J. Sinclair, E. Jacka, \& S. Cunningham (eds.), New patterns in global television: Peripheral vision, New York, NY: Oxford University Press.

26. Straubhaar JD (2007) World television: From global to local. Thousand Oaks, CA: Sage.

27. Wildman S, Siwek S (1988) International trade in films and television programs Cambridge, MA: Ballinger, UK.

28. Morley D (1992) Television, audiences and cultural studies. London, UK Routledge.

29. Cantor MG, Cantor JM (1986) American television in the internationa marketplace. Communication Research, 13: 509-520.

30. Straubhaar JD (1991) Beyond media imperialism: Asymmetrica interdependence and cultural proximity. Critical Studies in Mass Communication 8: 39-58.

31. Straubhaar JD (2003) Choosing national TV: Cultural capital, language, and cultural proximity in Brazil. In: M. G. Elasmar (eds), The impact of international television: A paradigm shift, Mahwah, NJ: LEA.

32. Fu WW (2006) Concentration and homogenization of international movie sources: Examining foreign film import profiles. Journal of Communication, 56: 813-835.

33. Fu WW, Sim C (2010) Explaining international country-to-country flow of theatrical films. Journal of Communication 60: 120-143.

34. Fu WW, Govindaraju A (2010) Explaining global box office tastes in Hollywood films: Homogenization of national audiences' movie selections. Communication Research 37: 215-238.

35. Definition of cultural diversity concepts.

36. Definition of types of vocabulary.

37. Neuendorf AK (2002) The Content Analysis Guidebook. New Delhi: Sage Publications.

38. Dake D (2005) Handbook of Visual Communication: Theory, Methods, and Media. Routledge Communication Series: An essay on Aesthetics theory. lowa State University. Lawrence Erlbaum Associates Publishers, NY. 